\title{
The Effect of Orem's Self Care Model on Physical Quality Of Life in Patients with Multiple Sclerosis
}

\author{
Masoud Khodaveisi ${ }^{1}$, Marzieh Rahmati², Gholamhosein Falahinia ${ }^{3 *}$, Manoucher \\ Karami $^{4}$, Mehd Molavi Vardanjani ${ }^{5}$ \\ 1- $\quad$ PhD, Associate Professor, Chronic Diseases (Home Care) Research Center, and Community Health \\ Nursing Department, Hamadan University of Medical Sciences, Hamadan, Iran. \\ 2- $\quad$ MSc in Medical Surgical Nursing, Nursing \& Midwifery school, Hamadan University of Medical \\ Sciences, Hamadan, Iran. \\ 3- Instructor, Chronic Diseases (Home Care) Research Center, and Community Health Nursing \\ Department, Hamadan University of Medical Sciences, Hamadan, Iran. (Corresponding Author), Tel: +98 918 \\ 8131165 Email: H.falahinia@gmail.com \\ 4- $\quad \mathrm{PhD}$, Associate Professor, Social Determinants of Health Research Center, Epidemiology Department, \\ Hamadan University of Medical Sciences, Hamadan, Iran. \\ 5- $\quad$ Instructor, Nursing \& Midwifery School, Hamadan University of Medical Sciences, Hamadan, Iran.
}

Received:7 July 2018

Accepted:11 Aug 2018

\begin{abstract}
Background \& Aim: Multiple sclerosis (MS) is a progressive disease of the central nervous system, which has debilitative effects on the quality of life of the patients due to its various physical complications. The present study aimed to assess the effects of using Orem's selfcare model on the physical dimensions of quality of life in MS patients.

Materials \& Methods: This quasi-experimental study was conducted on 74 patients with MS referring to the MS Association in Hamedan, Iran in 2014. The patients were selected via convenience sampling and randomly allocated to two groups of intervention and control. Data were collected using MSPHQOL-54 in the study groups. In addition, a training program was implemented for 2-4 sessions based on the extracted needs of the patients in the intervention group. After two months of the self-care program in the intervention group, MSPHQOL-54 was completed again by the two groups. Data analysis was performed using Chi-square, paired t-test, and independent t-test.

Results: Mean quality of life in all the physical dimensions was $57.2 \pm 20.5$ in the intervention group before the training program, which significantly increased to $67.5 \pm 15.3(\mathrm{P}=0.001)$. However, no such difference was observed in the control group.

Conclusion: According to the results, Orem's self-care model could improve the physical dimensions of quality of life in MS patients. Therefore, it is recommended that this model be applied to enhance the physical dimensions of quality of life in these patients.

Keywords: Orem's Self-care Model, Quality of Life, Multiple Sclerosis
\end{abstract}

How to cite this article:

Khodaveisi M, Rahmati M, Falahinia G, Karami M, Molavi Vardanjani M. The Effect of Orem's Self Care Model on Physical Quality Of Life in Patients with Multiple Sclerosis. Scientific Journal of Nursing, Midwifery and Paramedical Faculty. 2018; 3 (4) :24-35 URL: http://sjnmp.muk.ac.ir/article-1-140-fa.html

Copyright $(92018$ the Author (s). Published by Kurdistan University of Medical Sciences. This is an open access article distributed under the terms of the Creative Commons Attribution-Non Commercial License 4.0 (CCBY-NC), where it is permissible to download, share, remix, transform, and buildup the work provided it is properly cited. The work cannot be used commercially without permission from the journal. 


\section{بررسى تأثير بهكار تيرى التكوى خود مر اقبتى اورم بر ابعاد جسمى كيفيت زندكى بيماران مبتلا به مولتيّل اسكلروزيس}

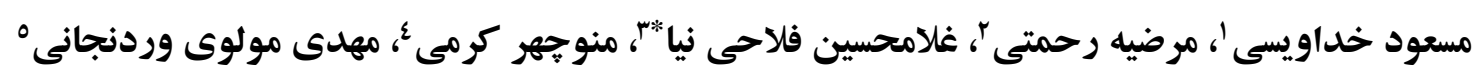

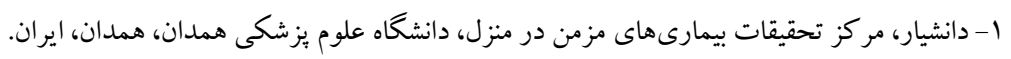

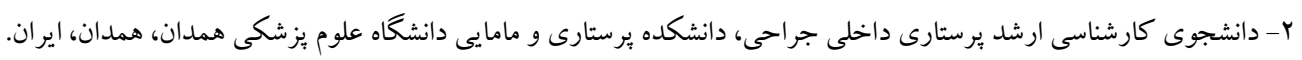

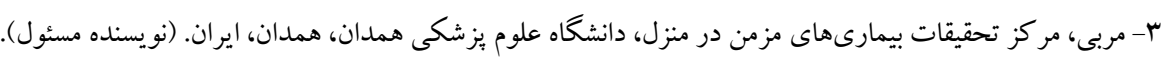

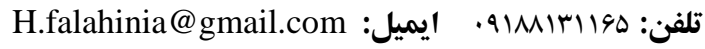

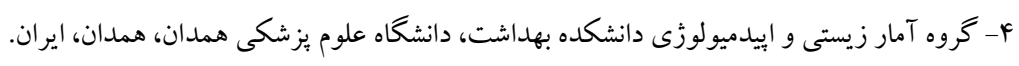

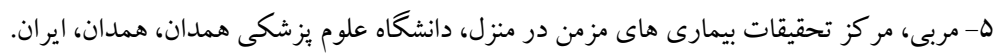

زمينه و هدف: بيمارى مولتييل اسكلروزيس يكك بيمارى بيش رونده سيستم عصبى مركزى است كه به دليل عوارض جسمى

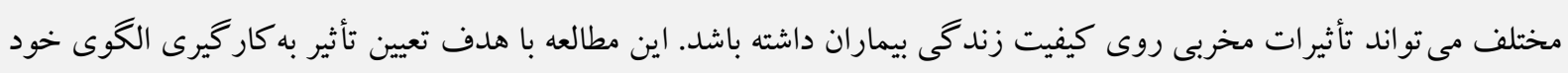

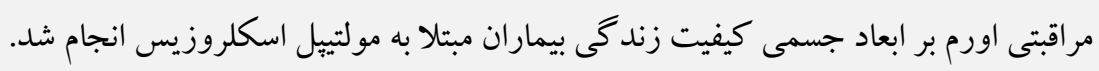

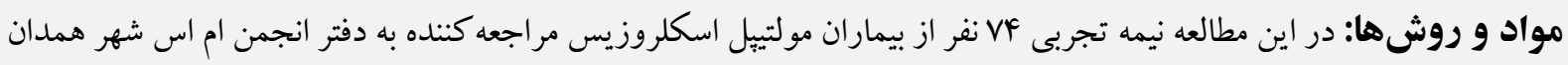

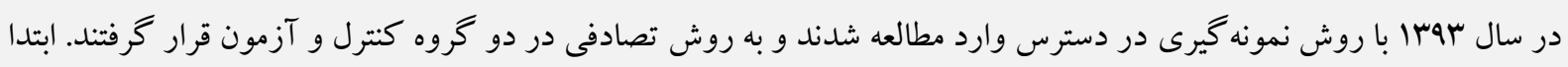

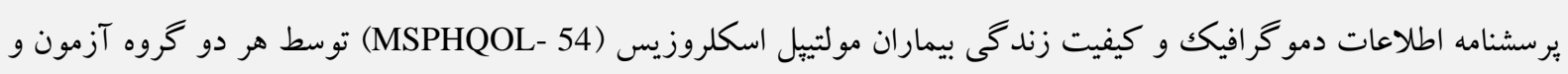

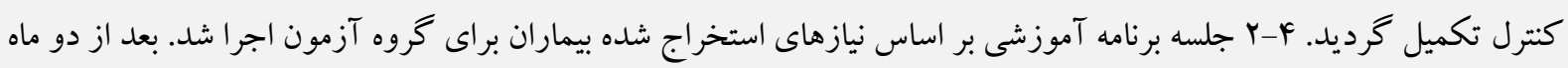

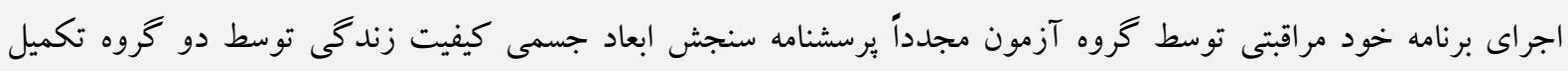

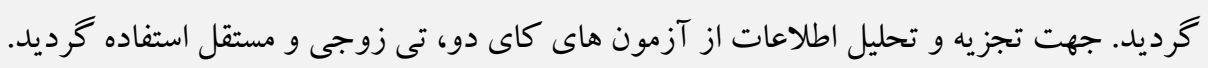

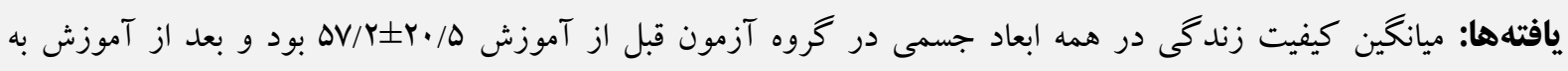

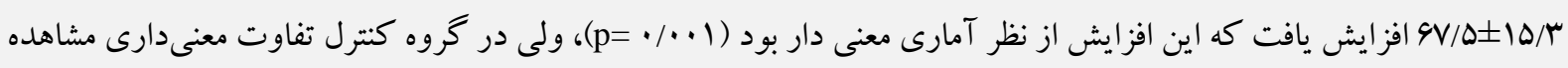

نتيجه كيرى: آموزش برنامه خود مراقبتى اورم موجب بهبود ابعاد جسمى كيفيت زندگى در بيماران مبتلا به مولتييل اسكلروزيس

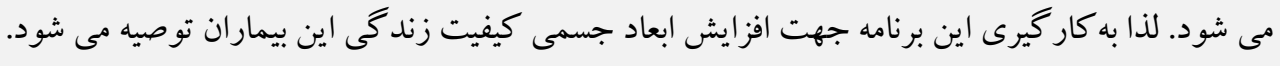

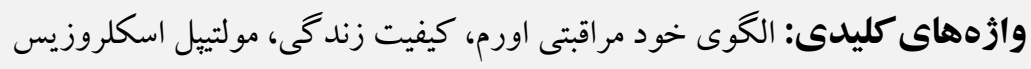

به عبارتى بيشتر در دهdهاى سوم و جهارم زندكى اتفاق مقدمه

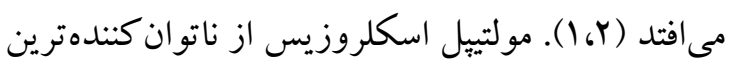
بيمارى مولتييل اسكلروزيس يك بيمارى مزمن غير بيمارىهاى عصبى مزمن در بالغين جوان مىباشد (r).

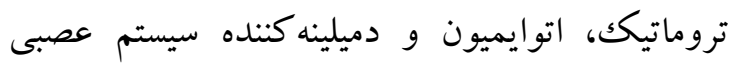

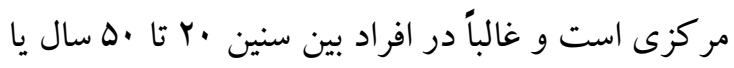


كيفيت زندگى هايين ترى برخوردارند (IF). كيفيت

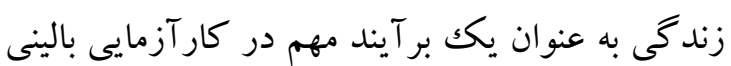
و مداخلات مراقبتهاى بهلاشتى، مطرح است (10) و امروزه در بيشتر مطالعات علمى (از جمله مطالعات

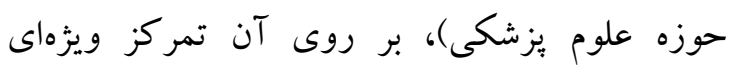

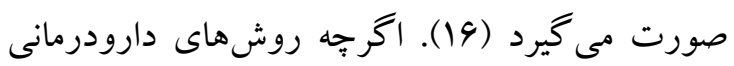
در بيماران مولتييل اسكلروزيس مىتواند در كاهش دفعات عود، شدت بيمارى و نيز كاهش بيشرفت بيمارى مؤثر واقع شود (IV)، اما اين روشها به ميزان كمى در درمان نشانها، بهبود عملكرد و ابعاد جسمى كيفيت زندكى اين افراد تأثير گذار است (1) (1). روشهاى مختلفى براى بهبود ابعاد جسمى كيفيت

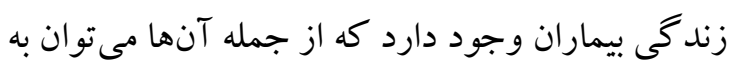
آموزش برنامه خود مراقبتى اشاره كرد. خود مراقبتى به به به توانايى افراد براى انجام فعاليتهاى مراقبت از خود برد كفته مىشود (19). فعاليتهاى خود مراقبتى مى تواند فرد را به سمت حفظ سلامتى و خوب بودن سوق دهد،

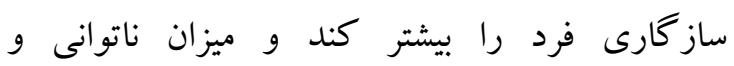
ازكارافتادكى بيماران و هزينههاى درمان را كاهش دهد (·Y). اهميت آموزش به بيمار در امر مراقبت از

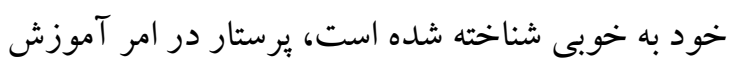
به بيمار و ارائه حمايتهاى لازم براى ايجاد يك بـ بر آيند مثبت كه همان فعال شدن بيمار در جهت كنترل بيمارى و انجام فعاليتهاى خود مراقبتى مىباشد، نقش كليدى دارد بطورى كه با بهبود مهارتهاى رفتارى در بيمار، احساس مسئوليت و خود كفائى در انجام مراقبت از خود افزايش يافته و تلاش بيشترى جهت كنترل بيمارى

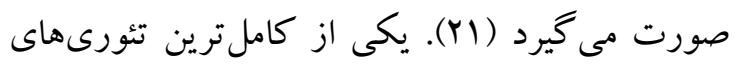

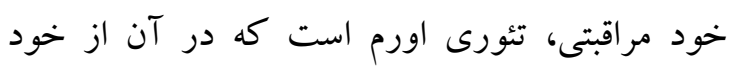
مراقبتى به عنوان يكك عملكرد تنظيمى نوع بشر نام برده

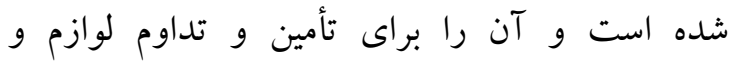

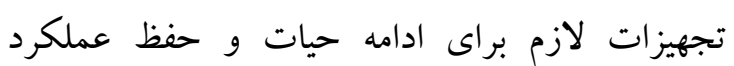

دوره بيمارى منحصر به فرد و غير قابل بيش بينى است و علت دقيق و درمان قطعى آن به خوبى بيشبينى نشده است (F). در حال حاضر r/ه ميليون نفر در سراسر دنيا به بيمارى مولتيبل اسكلروزيس مبتلا هستند. بالاترين ميزان شيوع شناخته شده بيمارى مولتيبل اسكلروزيس،

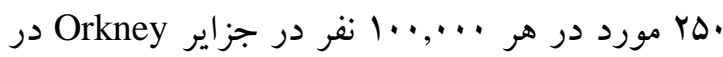

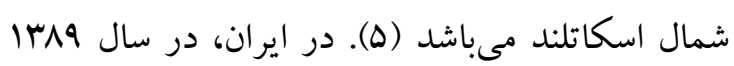
تعداد مبتلايان به مولتييل اسكلروزيس حدود •F هزار نفر اعلام شده است (9). اعتمادى فر و همكاران در سال سهسا، تعداد بيماران مولتييل اسكلروزيس را در استان همدان ..11 نفر برآورد كرد كه از اين تعداد

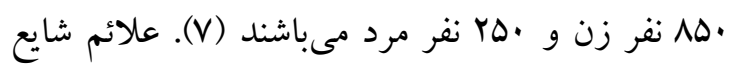
اين بيمارى شامل اختلال حسى، ضعف، گرفتخى

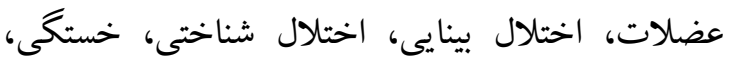
لرزش اندامها، اختلال در دفع ادرار و مدفوع، اختلال عملكرد جنسى، عدم تعادل، فراموشى، كاهش شنوايى،

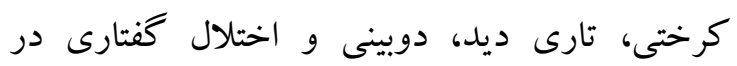
بيماران مىباشد (9،1). بيمارى به شدت نات ناتوان كننده معرفى مى كند ( • (). بيمارى مولتييل اسكلروزيس هزينه اقتصادى زيادى را به جامعه و خانواده تحميل مى كند

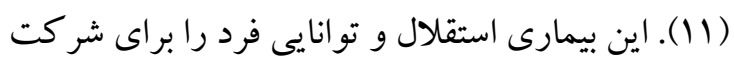
مؤثر در خانواده و اجتماع تهلديد مى كند و همه ابعاد

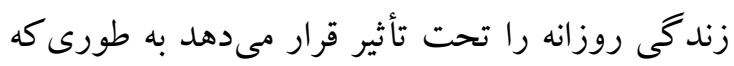
بيماران را به سوى فقدان احساس شايستگى و اطمينان از خود سوق مىدهد (YI). اين بيمارى بر جنبههاى مختلفى از زندگى افراد تأثير مى گذارد و اثرات منفى

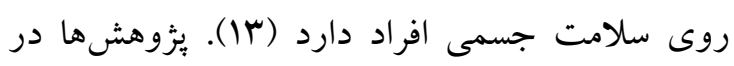

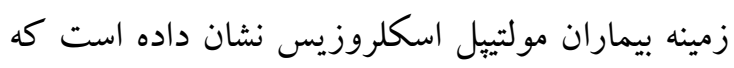
اين بيماران در مقايسه با افراد سالم جامعه و بيماران مبتلا به ديخر بيمارىهاى مزمن مثل صرع، ديابت، آرتريت روماتوئيد و بيمارىهاى التهابى روده از 
آزمون و كنترل قرار گرفتند. معيارهاى ورود به مطالعه شامل: نداشتن سابقه بيمارىهاى ديخر نظير اختلالات روانى و ساير بيمارىهاى مزمن (با توجه به يرونده بيمار

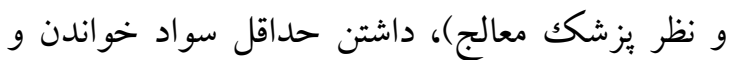
نوشتن، داشتن توانايى جسمى مراقبت از خود، سن بين

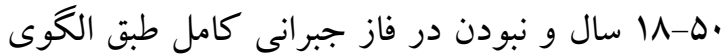
اورم بود. ابزار كردآورى دادهها برسشنامه مشخصات

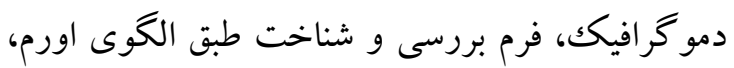
برسشنامه سنجش ابعاد جسمى كيفيت زندگى بيماران مولتيل اسكلروزيس Multiple sclerosis physical (MSPHQOL- 54) quality of life بررسى نيازهاى جسمى آموزشى هر يكك از واحدهاى يُزوهش، فرم بررسى و شناخت بر طبق الخوى اورم

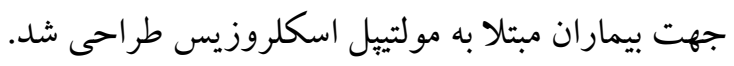
اين فرم شامل سوا لاتى در زمينه بررسى سطح آكاهى و نگرش مددجو نسبت به بيمارى، سطح مهارت و و عملكرد بيمار، ميزان درد بيمار، توانايى يادگيرى و و مشكلات حافظه، علائم بيمارى و بررسى تمايل بيمار جهت برنامه خود مراقبتى بود. فرم بررسى و شناخت بر طبق الكوى اورم شامل نيازهاى خود مراقبتى در سه به بهر حيطه نيازهاى خود مراقبتى همگانى، نيازهاى خود مراقبتى در هنگام انحراف سلامتى و نيازهاى خود مراقبتى رشد و تكامل تنظيم گرديد. از طريق فرم بررسى و شناخت بر طبق الگوى اورم، ابتدا نقص در خود مراقبى به عنوان تشخيصهاى يرستارى تعيين

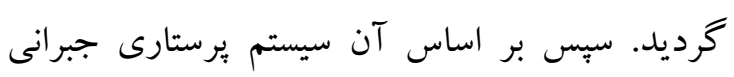
نسبى و سيستم يرستارى حمايتى آموزشى جهت بيماران گروه آزمون انتخاب گرديد. برسشنامه سنجش يُش

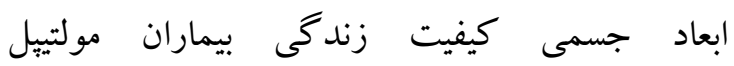
اسكلروزيس شامل ^ץ سؤال در قالب ^ بعد جزئى محدوديت در ايفاى نقش مرتبط با مشكلات جسمى، سلامت جسمى، انرزى، دركك از سلامتى، عملكرد
جسمانى و رشد فرد در محدوده طبيعى و متناسب براى

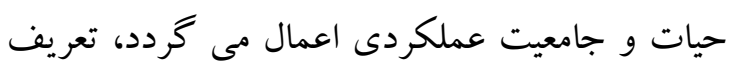
مى كند (Yr). الكوى مراقبت از خود زير بناى كار بالينى در مراقبت يرستارى است. تئورى اورم در تحقيق، آموزش و مديريت به كار مىرود،، اما كستردهـ

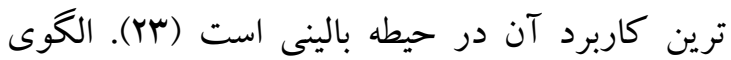
اورم مورد توجه بسيارى از ئزوهشخران عرصه بالينى

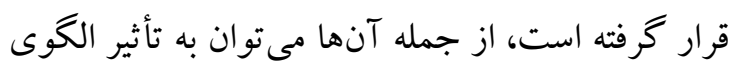
خود مراقبتى اورم بر كيفيت زندگى مبتلايان به برخى استى از بيمارىهاى مزمن اشاره كرد كه بهبود نسبى در كيفيت زندگى به دنبال اجراى اين الكو تائيد شده است هند (YY) بيمار در امر مراقبت از خود، طراحى شده باشد مى تواند اثرات مثتى بر كيفيت زندگى بيماران داشته باشد. در ايران در زمينه بررسى تأثير به كارگيرى برنامه خود

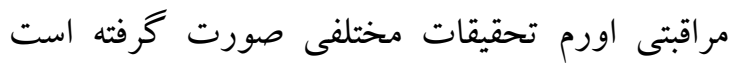
(YV-YO)

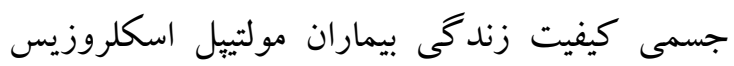
مطالعات محدودى انجام گرفته است. لذا بزوهشخران بر آن شدند تا مطالعهاى را با هدف تعيين تأثير

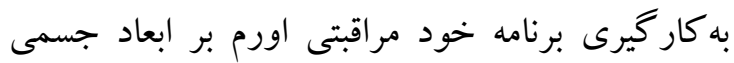

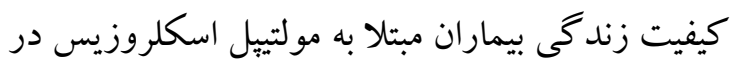
شهر همدان در سال سوس ا انجام دهند.

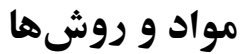
اين مطالعه به روش نيمه تجربى دو گروهى از نو نوع قبل و بعد از مداخله روى VF بيمار مبتلا به مولتيبل اسكلروزيس مراجعه كننده به دفتر انجمن ام اس مستقر در بيمارستان فرشجيان شهر همدان در سال سوسا انجام شد. ابتدا VF بيمار با توجه به معيارهاى ورود به مطالعه

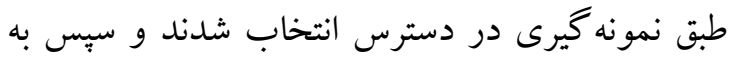
روش بلوككبندى جايگشتى در دو گروه PV نفرى 
r جلسه •r Pقيقهاى اجرا شد كه در هر جلسه حداكثر 9 بيمار و 9 همراه بيمار حضور داشتند. محل اجراى آموزشها دفتر انجمن ام اس مستقر در بيمارستان فرشيّان شهر همدان بود. به منظور بِايش افراد و

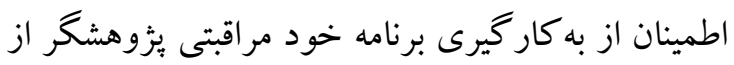
طريق تماس تلفنى بر نمونهها نظارت داشت. گروه كنترل فقط مراقبتهاى روتين انجمن را دريافت كردند. بعد از دو ماه اجراى برنامه خودمراقبتى در

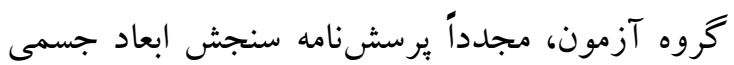
كيفيت زندگى توسط هر دو گروه آزمون و كنترل

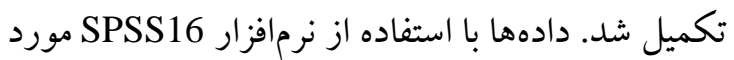
تجزيه و تحليل قرار گرفت. جهت تجزيه و تحليل دادهها از آزمونهاى كاى دو، تى مستقل و زوجى استفاده خرديد.

\section{يافتهها}

يافتهاى حاصل از مطالعه حاضر نشان داد كه اكثر

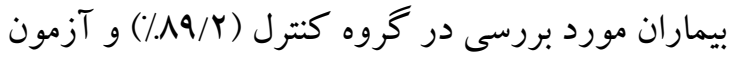

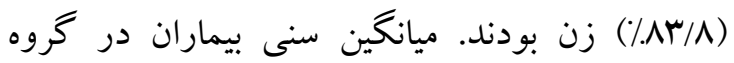
كنترل ץ./4 و در گروه آزمون ه/سM سال بود. اكثر بيماران شركت كننده در گروه كنترل (Vه/V) آزمون (س/.) متأهل بودند. از نظر سطح تحصيلات

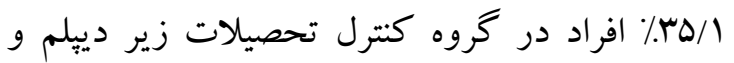

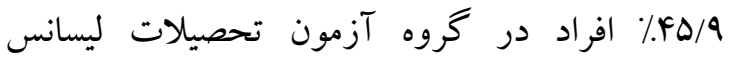
داشتند. ميانگين مدت بيمارى در گرروه كنترل 9/9 و در

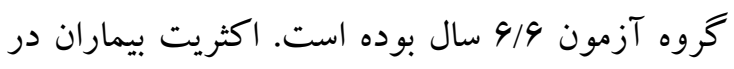
هر دو گروه كنترل ( بودند. دو گروه از نظر توزيع متغيرهايى نظير سن، مدت بيمارى، جنسيت، وضعيت تا هل، سطح تحصيلات، وضعيت اشتغال تفاوت معنىدارى نداشتند و همسان

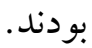

جنسى، عملكرد اجتماعى، رضايت از عملكرد جنسى

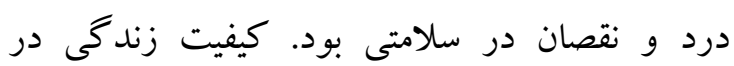
محدودهى صفر تا صد مىباشد. نمرهى بيشتر نشاندهندهى كيفيت زندگى بالاتر است. اين مقياس توسط باربارا ويكرى در دانشگاه كاليفرنيا در سال 190ه براى بيماران مولتيل اسكلروزيس طراحى شده است. اعتبار يرسشنامه در مطالعات مختلف خارج از

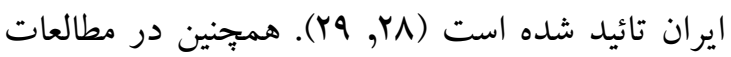
داخل ايران نيز اعتبار برسشنامه مورد تائيد قرار گرفته است. بايايى ابزار با ضريب همبستخى و^ه/. مورد تائيد قرار كرفته است ( • (ץ).

״س از كسب معرفىنامه كتبى از معاونت محترم يزٔوهشى دانشكاه علوم بزشكى همدان و اخذ مجوز لازم و تبيين اهداف يزّوهش براى واحدهاى بيزوهش و

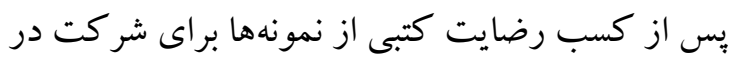

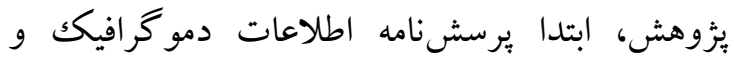
برسشنامه سنجش ابعاد جسمى كيفيت زندگى توسط

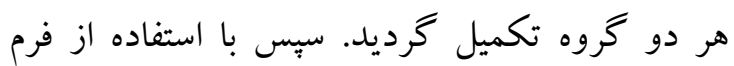
بررسى و شناخت اورم مشكلات بيماران و نيازهاى جسمى خود مراقبتى گروه آزمون استخراج شد. برنامه خود مراقبتى بر اساس نيازسنجى انجام شده از منابع

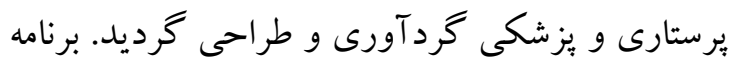
مراقبتى طراحى شده شامل سيستم برستارى جبرانى نسبى و سيستم برستارى حمايتى آموزشى بود كه فرد مبتلا به مولتيل اسكلروزيس را در برآورده كردن نيازهاى مراقبت از خود مشار كت مىدهد تا مراقبت از خود را بدون وابستكى به ديخران يا با كمكك انجام

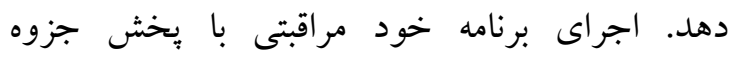

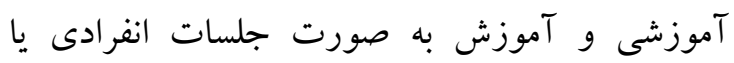

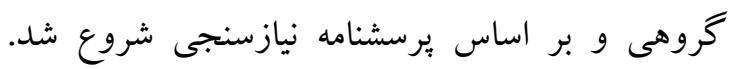

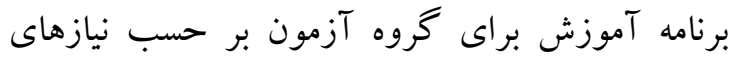

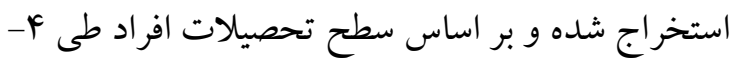


جدول ا: ويزگى هاى فردى واحدهاى مورد مطالعه

\begin{tabular}{|c|c|c|c|c|c|c|}
\hline \multirow{2}{*}{$\mathrm{p}$} & \multicolumn{2}{|c|}{ كروه آزمون } & \multicolumn{2}{|c|}{ كروه كنترل } & \multirow{2}{*}{ متغير } & \\
\hline & درصد & ت تعداد & درصد & ت تعداد & & \\
\hline$\cdot / 1$ & $r \Delta / 1$ & ir & $r \wedge / 1$ & 9 & $r \cdot-r \cdot$ & \multirow{3}{*}{ سن سن } \\
\hline & FN/9 & 11 & $M F / F$ & 11 & $r \cdot-r \cdot$ & \\
\hline & $19 / 4$ & 4 & $\mathrm{rV} / \mathrm{\Delta}$ & ir & بالاى f. & \\
\hline \multirow{2}{*}{$\cdot / V^{F}$} & $\Lambda r / \Lambda$ & M & $\wedge \mathrm{V} / \mathrm{\Delta}$ & ү^ & 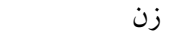 & \multirow[t]{2}{*}{ جنسيت } \\
\hline & $19 / 4$ & 9 & $1 Y / \Delta$ & F & مرد & \\
\hline \multirow{2}{*}{$\cdot / r$} & rV & 1. & $10 / 9$ & $\Delta$ & مجرد & \multirow{2}{*}{ وضعيت تا هل } \\
\hline & vr & YV & $\Lambda F / F$ & rV & متأهل & \\
\hline \multirow{4}{*}{$\cdot / / F$} & $1 N / 9$ & v & $\mathrm{rV} / \mathrm{\Delta}$ & ir & زير ديِم & \multirow{4}{*}{ سطح تحصيلات } \\
\hline & rq/V & 11 & 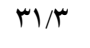 & 1. & دييلم & \\
\hline & $r \Delta / 1$ & ir & $r \Delta / 1$ & v & ل ليسانس & \\
\hline & $\Delta / F$ & r & $9 / \pi$ & r & فوق ليسانس & \\
\hline \multirow{4}{*}{$\cdot / M$} & $F F / F$ & 19 & $r V / \Delta$ & ir & كمتر از ه سال & \multirow{4}{*}{ مدت بيمارى } \\
\hline & $r \mu / r$ & Ir & $r F / F$ & 11 & · إ-ه سال & \\
\hline & $11 / 1$ & F & $9 / \pi$ & r & ها--· سال & \\
\hline & $11 / 1$ & F & $r q / 1$ & $\vee$ & بيش از ها سال & \\
\hline \multirow{4}{*}{$\cdot 19$} & $r \Delta / q$ & IV & $\Delta 9 / \Gamma$ & 11 & خانه دار & \multirow{4}{*}{ اشتغال } \\
\hline & $r Y / F$ & ir & $r 1 / 9$ & 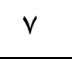 & بيكار & \\
\hline & $\Lambda / 1$ & $r$ & $9 / \pi$ & r & آزاد & \\
\hline & $1 \% / \Delta$ & $\Delta$ & $10 / 9$ & $\Delta$ & كارمند & \\
\hline
\end{tabular}

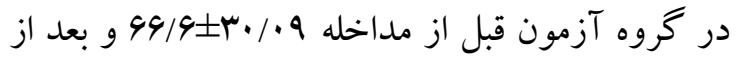
مداخله VY/VIYDQ بود كه اين افزايش از نظر آمارى

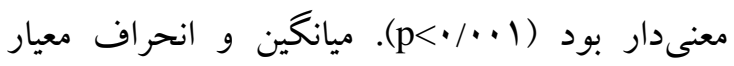
كيفيت زندكى در بعد سلامت جسمى در گروه آزمون

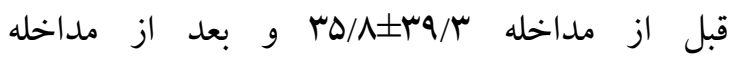

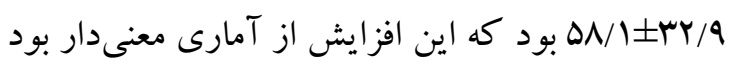

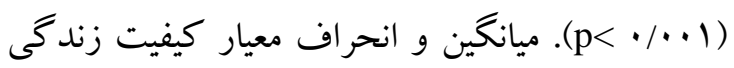
در بعد انرزى قبل از مداخله در كروه آزمون  FV/I ب بود، آزمون آمارى تى زوجى اختلاف

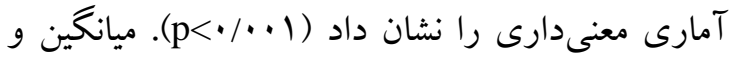

اختلاف ميانگين كيفيت زندگى در ابعاد سلامت جسمى در دو گروه آزمون و كنترل قبل از مداخله از

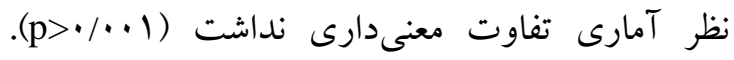

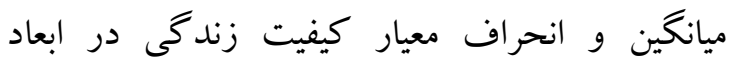
سلامت جسمى در گروه آزمون قبل از مداخله $\Delta V / Y \pm Y \cdot \Delta$

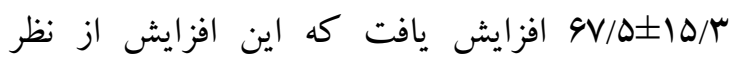
آمارى معنىدار بود ( (1) (p)، اين افزايش در تمام ابعاد سلامت جسمى در گروه آزمون معنىدار بود.

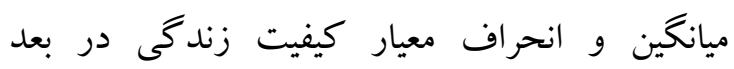
محدوديت در ايفاى نقش مرتبط با مشكلات جسمى 
معيار كيفيت زندگى در بعد رضايت از عملكرد جنسى

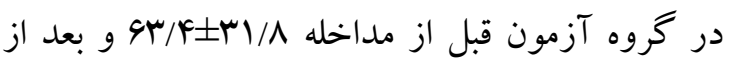
مداخله

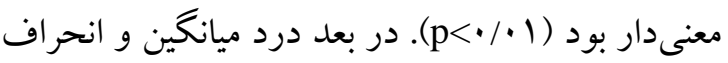

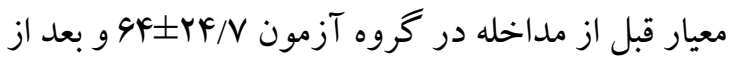
مداخله VV/FIO/A بود كه اين افزايش از نظر آمارى

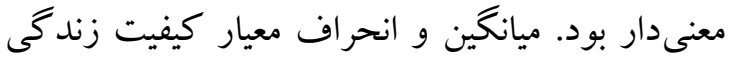
در بعد نقصان در سلامتى در گروه آزمون قبل از مداخله كه از نظر آمارى اين اختلاف معنىدار بود .$(\mathrm{p}<\cdot / \cdot \cdot 1)$
انحراف معيار كيفيت زندكى در بعد درك از سلامتى

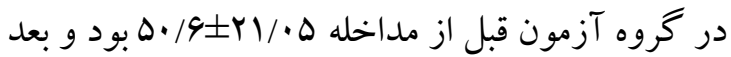
از مداخله معنى ميانگين و انحراف معيار در گروه آزمون قبل از مداخله

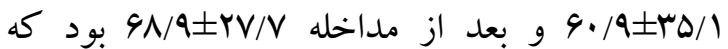
آزمون تى زوجى اين افزايش را معنىدار نشان داد

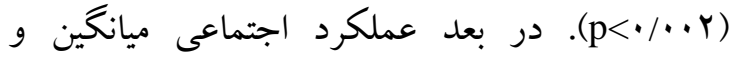

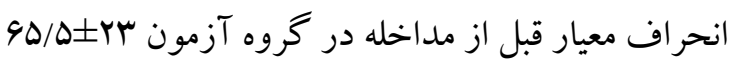
و بعد از مداخله V9/19/9 بود كه اين افزايش از نظر

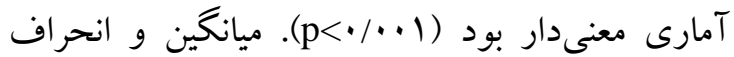

جدول r: ميانكين ابعاد جسمى كيفيت زند در بيماران مبتلا به مولتيِل ديل اسكلروزيس

\begin{tabular}{|c|c|c|c|c|c|c|}
\hline \multicolumn{3}{|c|}{ كروه آزمون } & \multicolumn{3}{|c|}{ كروه كنترل } & \multirow[t]{2}{*}{ متغير } \\
\hline $\begin{array}{c}\text { آزمون } \\
\text { (p-value) }\end{array}$ & بعد از مداخله & ق قبل از مداخله & $\begin{array}{c}\text { آزمون } \\
\text { (p-value) }\end{array}$ & بعد از مداخله & قبل از مداخله & \\
\hline$\cdot / \cdot \cdot 1$ & $V Y / V \pm r \Delta / \Delta$ & $99 / 9 \pm r \cdot / \cdot 9$ & $\cdot / V$ & $q \cdot / r \pm r V / V$ & $q \cdot / V \pm r V / q$ & محدوديت در ايفاى نقش \\
\hline$\cdot / \cdot \cdot 1$ & $\Delta \Lambda / I \pm r r / q$ & $r \Delta / \wedge \pm r q / \Gamma$ & $\cdot / \cdot r$ & $r Y / A \pm M r / Y$ & $r q / \Lambda \pm r q / \cdot v$ & سلامت جسمى \\
\hline$\cdot / \cdot 1$ & $F V / I \pm \mid \Lambda / I$ & $F r / r \pm I N / \Delta$ & $\cdot / 1$ & $r q / 1 \pm r \cdot / v$ & $r \cdot / f \pm r \mid / \cdot r$ & انرزى \\
\hline$\cdot / \cdot 1$ & $\Delta \Lambda / Y \pm 19 / \Lambda$ & $\Delta \cdot / 9 \pm r \mid / \cdot \Delta$ & $\cdot / 1$ & $\Delta 1 / \wedge \pm 1 / / 9$ & $\Delta F / Y \pm r \mid / 1$ & دركك از سلامتى \\
\hline$\cdot / \cdot r$ & $9 \Lambda / 9 \pm r V / V$ & $q \cdot / q \pm r \Delta / 1$ & $\cdot / r$ & $q V / r \pm r \cdot / 9$ & $V \cdot / \pm r \mid / r$ & عملكرد جنسى \\
\hline$\cdot / \cdot \cdot 1$ & $v 9 / 1 \pm 19 / 9$ & $90 / \Delta \pm r r$ & $\cdot / 1$ & $G F / \Lambda \pm r \cdot / F$ & $99 / 9 \pm r \cdot / V$ & عملكرد اجتماعى \\
\hline$\cdot / \cdot 1$ & $V r / r \pm r \Delta / q$ & $G \Gamma / F \pm r \mid / \Lambda$ & $\cdot / f$ & $\Delta q / r \pm r \cdot / r$ & $G Y / \Delta \pm r Y / 1$ & رضايت از عملكرد جنسى \\
\hline$\cdot / \cdot 1$ & $W / F \pm 1 ه / 9$ & $G F \pm Y Y / V$ & .1 .9 & $G r / \Lambda \pm r \Delta / 1$ & $9 \Delta / 9 \pm r r / r$ & 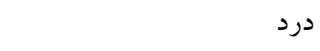 \\
\hline$\cdot / \cdot 1$ & $99 / F \pm Y F / V$ & $\Delta \Lambda / r \pm r Q / \Lambda$ & .1 .9 & $\Delta F / \Delta \pm r \Delta / F$ & $\Delta \Lambda / \backslash \pm Y \Lambda / I$ & نقصان در سلامتى \\
\hline$\cdot / \cdots 1$ & $q V / \Delta \pm 1 \Delta / r$ & $\Delta V / r \pm r \cdot / \Delta$ &.$/ \cdot 1$ & $\Delta F / \Delta \pm 19 / V$ & $\Delta V / Y \pm 19 / V$ & كيفيت زندگى در ابعاد جسمى \\
\hline
\end{tabular}

\section{بحث و نتيجه گيرى}

نتايج حاصل از اين مطالعه تأثير برنامه خود مراقبتى اورم بر تمام ابعاد جسمى كيفيت زندگى بيماران

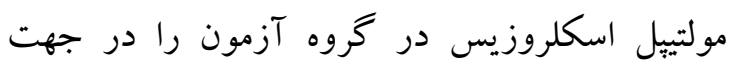
مثبت نشان مىدهد. ميانگين ابعاد جسمى كيفيت زندكى در بيماران مولتييل اسكلروزيس در اين مطالعه
در گروه كنترل ميانگين و انحراف معيار كيفيت

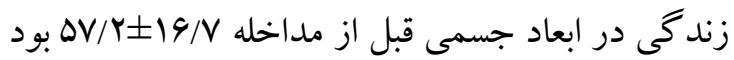
و دو ماه بعد معنى

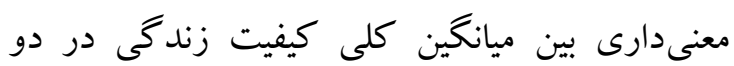

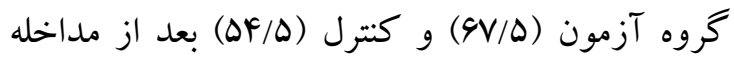

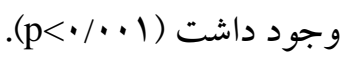


ايفاى نقش مرتبط با مشكلات جسمى بود و در ساير

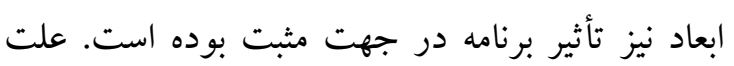
تأثير بيشتر برنامه در بعضى ابعاد نسبت به ساير ابعاد

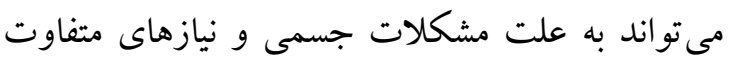

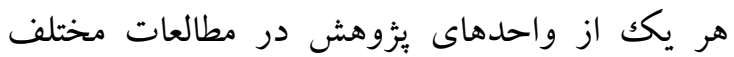
باشد. Petajan و همكاران (rV) در يُزوهشى تحت عنوان (اتأثير ورزش هوازى بر تناسب اندام و كيفيت

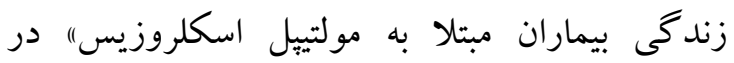
ايالاتمتحده نشان دادند كه اجراى اين برنامه 10 هفتهاى در قالب هر هفته سه جلسه ·f دقيقهاى، باعث بهبود در بعد ايفاى نقش بيماران مى گردد كه در مطالعه هر هركه

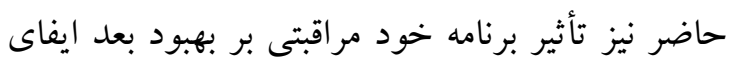
نقش بيماران مولتييل اسكلروزيس مشاهده شد. در

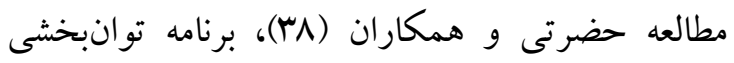
باعث افزايش معنادارى در همه ابعاد كيفيت زندگى ونى بهجز بعد عملكرد جنسى بيماران مولتيِل اسكلروزيس إنس بعد از يكك ماهو سه ماه از اجراى مداخله شد. از لحاظ بهبودى در عملكرد جسمى، انرزى، درد جسمى و سرزندگى با مطالعه حاضر همسو مىباشد اما از لحاظ

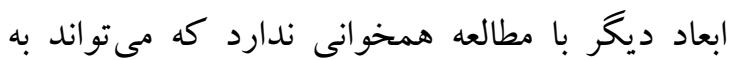
علت نوع برنامه توانبخشى باشد جرا كه در مطالعه

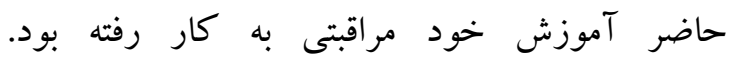
Zalweski

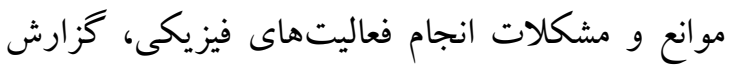

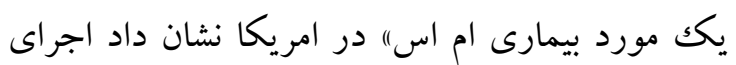
برنامه ^ هفتهاى ورزش بر كيفيت زندگى بيماران مبتلا به ام اس منجر به بهبود عملكرد جسمى و همجنين

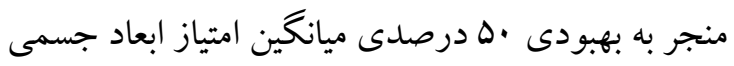

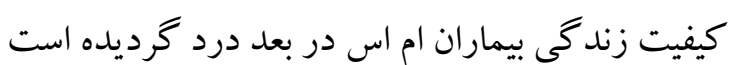
به طورى كه از عدد ها به 9V/D رسيده است؛ اما بر بعد محدوديت نقش مرتبط با مشكلات جسمى بى تأثير است. نتيجه تحقيق فوق در بعد عملكرد جسمى و درد

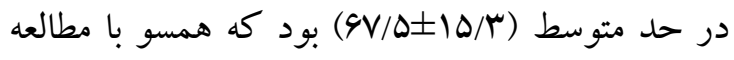
ترقى و همكاران بود. ترقى و همكاران در مازندران به مدونه بررسى كيفيت زندگى بيماران عضو انجمن مولتييل

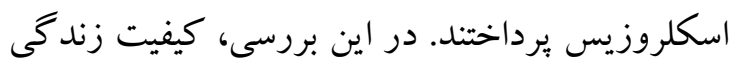
بيماران در تمام شاخصها در حد متوسط بود (اسل). ميانگين ابعاد جسمى كيفيت زندكى در بيماران مولتييل

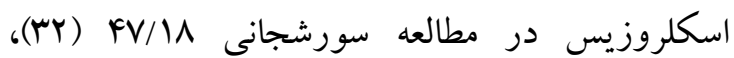
حارث آبادى كه در اين مطالعات نيز كيفيت زندگى بيماران در حد متوسط گزارش شده است. مطالعه حاضر نيز همسو با يا نتايج مطالعات فوق مىباشد. ناجى و همكاران كه تأثير الكوى خود مراقبتى اورم را بر كيفيت زندگى بيماران تحت همودياليز سنجيده بود حاكى از آن است كه الكوى خود مراقبتى اورم باعث افزايش معنادار در تمامى ابعاد آن مىشود (هآ). نتايج مطالعهاى كه توسط براز و همكاران با عنوان تأثير

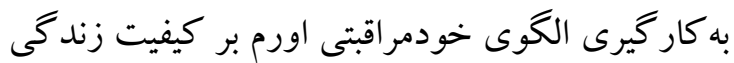
سالمندان انجام شد، نشان داد كه آموزش برنامه خود مراقبتى اورم باعث بهبود كيفيت زندكى در همه ابعاد گرديد (Y)). نتايج مطالعه حاضر با دو مطالعه فوق همسو مىباشد. در بعد سلامت جسمى تأثير اين برنامه نسبت به ساير ابعاد بيشتر بود. در ساير ابعاد نيز تأثير

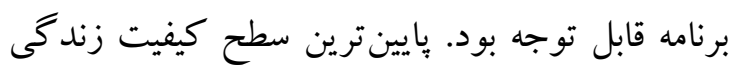

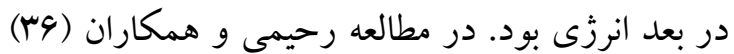
كه به ارزيابى تأثير برنامه خود مراقبتى اورم بر كيفيت

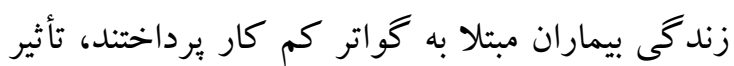
مثبت اين برنامه را بر بيماران مبتلا به كواتر كم كار

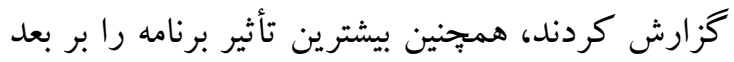
درد گزارش كردند. در مطالعه مسعودى و همكاران

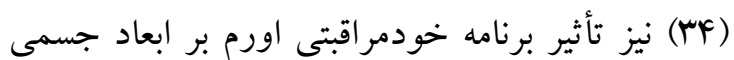

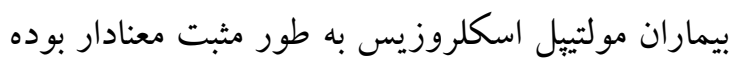

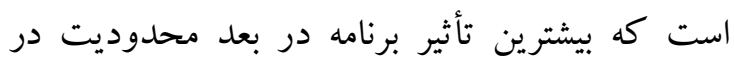


بيماران تداوم يابد و متناسب با سطح دركك آنها طر احى شود، مى تواند موجب دستيابى به نتايج مثبت در عملكرد سلامت شود. بدين ترتيب استفاده از الكوهايى كه قادر به ترغيب مددجو و توجه به مشاركت بيمار در امر مراقبت از خود مىباشد مىتواند موجب افزايش كيفيت زندكى باشد و استفاده از اين مدل اطلاعات بارزشى فراهم آورده و مىتواند در تحقيقات يرستارى، بررسى و شناخت و ارزشيابى سيستم مراقتى بيماران مولتيّل اسكلروزيس كاربرد داشته باشد. از محدوديتهاى اين مطالعه وجود تفاوتهاى فردى افراد مورد مطالعه بود كه اين مورد خارج از كنترل است. به دليل محدوديت زمانى، عدم انجام بيخيرىهاى درمانى در طولانىمدت جهت بررسى ميزان تأثير برنامه

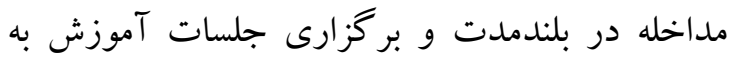
صورت فشرده از ديخر محدوديتهاى اين مطالعه بود. امكان كسب اطلاعات از منابع ديخر مانند رسانهاى جمعى، اينترنت، كتب موجود، يزشك بيمار و دوستان و آشنايان وجود داشت كه خارج از كنترل يُوهشگ

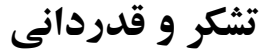

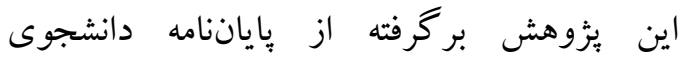

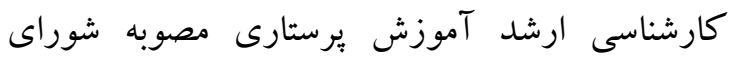

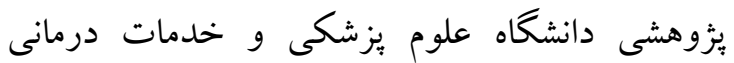

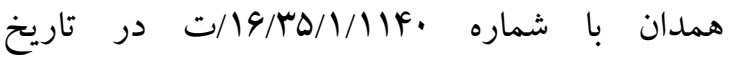

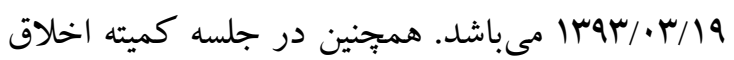
دانشگاه علوم بزشكى و خدمات درمانى همدان مورخ

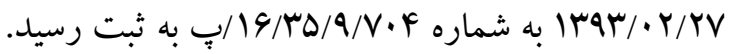
نويسند كان مقاله از همكارى مسئولين محترم دانشگاه

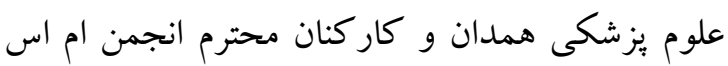
شهر همدان و تمامى بيماران و خانو اده آنان كه صادقانه
با تحقيق حاضر همخوانى دارد اما در بعد محدوديت نقش در رابطه با مشكلات جسمى مغايرت دارد. شايد بتوان كفت اجراى برنامه ورزشى بايد متناسب با توانايى

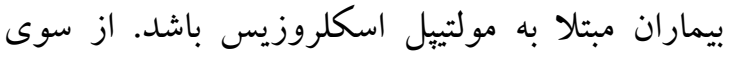
ديخر با توجه به ماهيت مزمن بيمارى مولتيبل اسكلروزيس لازم است برنامهها متناسب با ماهيت اين بيمارى تدوين و اجرا گردند و طول مدت اجراى برنامه افزايش يابد. نتايج حاصل از يثوهش حاضر نشان داد

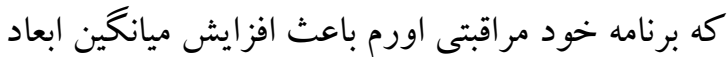
جسمى كيفيت زندگى در بعد انرزى در بيماران مبتلا به مولتيِل اسكلروزيس مىشود كه با مطالعه Rampello و همكاران همسو مىباشد. Rampello و همكاران (F•) در مطالعه خود با عنوان (تأثير ورزشهاى هوازى بر توانايى حركت و تحمل بهينه ورزش در بيماران

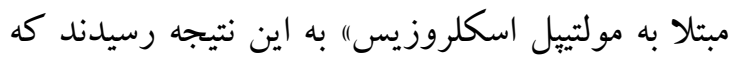
سطح انرزى افراد بعد از مداخله افزايش يافته است. Hara اثربخشى برنامه خودمر اقبتى حرفهاى در بيماران مولتيبل اسكلروزيس يرداختند. نتايج مطالعه افزايش معنادارى را در نمرات كيفيت زندگى در بعد سلامت ذهنى و ميزان مستقل بودن بيماران در گروه مداخله نشان داد

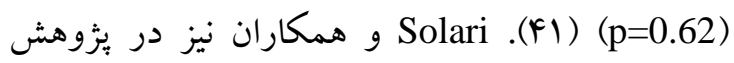

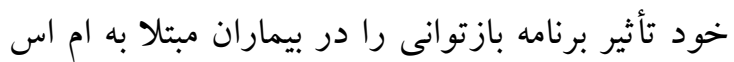

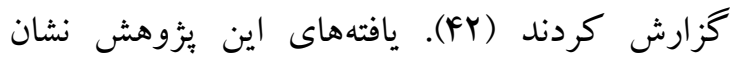
مىدهد كه انجام فعاليتهاى خود مراقبتى توسط بيماران مبتلا به مولتييل اسكلروزيس كاملاً امكانيذير مىباشد و با آموزش و اجراى برنامه خود مر اقبتى طبق

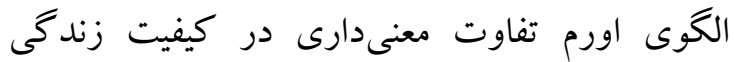
بيماران مبتلا به مولتيبل اسكلروزيس ايجاد مىشود، به به به طورى كه اجراى برنامه خود مراقبتى با افزايش ميزان

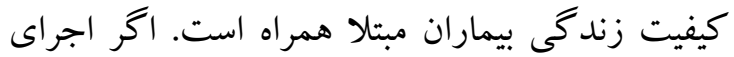
برنامه خود مراقبتى بر اساس نيازهاى خود مراقبتى 


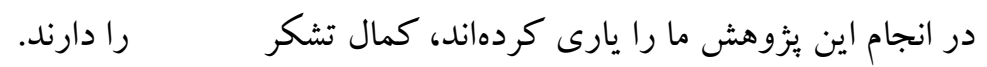

\section{References}

1- Brass SD, Duquette P, Proulx-Therrien J, Auerbach S. Sleep disorders in patients with multiple sclerosis. Sleep medicine reviews. 2010;14(2):121-9.

2- Da Silva AM, Vilhena E, Lopes A, Santos E, Gonçalves MA, Pinto C, et al. Depression and anxiety in a Portuguese MS population: associations with physical disability and severity of disease. Journal of the neurological sciences. 2011;306(1):66-70.

3- Zabihi A, Ebrahimi H, Rashid-Farrokhi F, Ramezani A. The relationship between multiple sclerosis and various class I HLAs. Medicine Journal. 2004:13-4. [Persian].

4- Dennison L, Moss-Morris R, Chalder T. A review of psychological correlates of adjustment in patients with multiple sclerosis. Clinical psychology review. 2009;29(2):141-53.

5- Hauser S, Goodin D, Longo D. Multiple sclerosis and other demyelinating diseases, Harrison's principles of internal medicine. New York: McGraw Hill; 2012.

6- Shahbeigi. S. 7th International Congress of Multiple Sclerosis. 2010 November 4. [Persian]

7- Etemadifar M, Sajjadi S, Nasr Z, Firoozeei TS, Abtahi S-H, Akbari M, et al. Epidemiology of multiple sclerosis in Iran: A systematic review. European neurology. 2013;70(5-6):356-63. [Persian].

8- Saman-Nezhad B, Rezaee T, Bostani A, Najafi F, Aghaei A. Epidemiological Characteristics of Patients with Multiple Sclerosis in Kermanshah, Iran in 2012. J Mazandaran Univ Med Sci. 2013;23(104):97-101. [Persian].

9- Broekmans T, Roelants M, Alders G, Feys P, Thijs H, Eijnde BO. Exploring the effects of a 20-week whole-body vibration training programme on leg muscle performance and function in persons with multiple sclerosis. Journal of Rehabilitation Medicine. 2010;42(9):866-72.

10- Yazdani M, Hemayattalab R, Sheikh M, Etemadifar M. The Effect of a Selected Aquatic Exercise on Balance in Subject With Multiple Sclerosis (MS). Journal of Research in Rehabilitation Sciences. 2013;9(2):143-52. [Persian].

11-Davis WM. Multiple sclerosis: continuing mysteries and current management. Drug Topics. 2000;144(12):93-102.

12- Brunner L, Suddarth D. Text book of medical -surgical nursing. 11 ed. Philadelphia: J.B: Lippincott; 2010.

13- NikBakht H, Ebrahim K, RezaeShirazi R, MasuodiNezhad M. Effects of selected combined training on muscle strength in Multiple Sclerosis patients. HealthMED. 2012;6(1):96-102. [Persian].

14-Shamili F, Zare H, Oraki M. The Predicting Quality of Life Based on Illness Perception in Multiple Sclerosis Patients. Urmia Medical Journal. 2013;24(6):379-92. [Persian].

15- Group E-BMW, Rennie D, Guyatt GH. Fayers PM, Machin D. Quality of life: assessment, analysis and interpretation. New York: Wiley; 2000. 
16- Polonsky WH. Understanding and assessing diabetes-specific quality of life. Diabetes spectrum. 2000;13(1):36-41.

17-Goodin D, Frohman E, Garmany G, Halper J, Likoski W, Lublin F. Disease modifying therapies in multiple sclerosis. Neurology. 2002; 58 (2): 169-78.

18- Freeman J, Thompson A, Fitzpatrick R, Hutchinson M, Miltenburger C, Beckmann K, et al. European Study Group Interferon-beta1b in Secondary Progressive MS: Interferon- $\beta 1 \mathrm{~b}$ in the treatment of secondary progressive MS. Impact on quality of life. Neurology. 2001;57:1870-5.

19- Mohammad Hassani M, Farahani B, Zohour A, Panahi Azar R. Self-care ability based on Orem's theory in individuals with coronary artery disease. Iranian Journal of Critical Care Nursing. 2010;3(2):87-91. [Persian].

20- Connell M. Self care is hairpin indigent patients with heart failure. Eur J Cardiovasc Nurs. 2008;23(3):223-30.

21- Memarian R. Application of nursing concepts and theories: Tehran: Tarbiat Modares University; 2011. [Persian].

22- Vasilieva IA. Quality of life in chronic hemodialysis patients in Russia. Hemodialysis International. 2006;10(3):274-8.

23-Orem's Self-Care Framework [Internet]. 2010. Available from: http://proquest.umi.com.

24- Mahmoudi A. The Effect of Self-care Program on Foot Healing in Diabetic Patients. Shahrekord University of Medical Sciences Journal. 2005. [Persian].

25-Hashemi F, Dolatabad FR, Yektatalab S, Ayaz M, Zare N, Mansouri P. Effect of Orem Self-Care Program on the Life Quality of Burn Patients Referred to Ghotb-alDin-e-Shirazi Burn Center, Shiraz, Iran: A Randomized Controlled Trial. International Journal of Community Based Nursing and Midwifery. 2013;2(1):40-50. [Persian].

26- Baraz S, Rostami M, Farzianpor F, Rasekh A. Effect of Orem Self Care Model on ederies' quality of life in health care centers of Masjed Solaiman in 2007-2008. Arak Medical University Journal. 2009;12(2):51-9. [Persian].

27- Naji H, Nikhbakht Nasrabadi A, Shaban M, Saebnia R. The effect of using Orem's model of self-care on recovery of patients with heart failure. Iranian Journal of Nursing and Midwifery Research. 2010;14(4):174-9. [Persian].

28- Tepavcevic D, Kostic J, Basuroski I, Stojsavljevic N, Pekmezovic T, Drulovic J. The impact of sexual dysfunction on the quality of life measured by MSQoL-54 in patients with multiple sclerosis. Multiple sclerosis. 2008; 14 (8): 131-36.

29- Turpin K, Carroll L, Cassidy J, Hader W. Deterioration in the health-related quality of life of persons with multiple sclerosis: the possible warning signs. Multiple Sclerosis. 2007;13(8):1038-45.

30- Masoudi R, Mohammadi I, Nabavi S, Ahmadi F. The effect of Orem based self-care program on physical quality of life in multiple sclerosis patients. Shahrekord University of Medical Sciences Journal. 2008. [Persian].

31- Taraghi Z, Ilali E, Abedini M, Zarvani A, Khoshnama I, Mohammadpour R, et al. Quality of life among multiple sclerosis patients. Iran Journal of Nursing. 2007;20(50):51-9. [Persian]. 
32-Sureshjani SH, Eslami A, Hassanzadeh A. The Quality of Life among Multiple Sclerosis Patients in Isfahan, Iran. Journal of Health Systems Research. 2012;7(5):571-79. [Persian].

33- Haresabadi M, monghi HK, Foroughipoor M, Mazloum R. Quality of Life among Multiple Sclerosis Patients in mashhad 2009. Journal of North Khorasan University of Medical Sciences 2010;2(4):7-12. [Persian].

34-Masoudi R, Mohammadi E, Nabavi M, Ahmadi F. The effect of Orem's self-care theory on the quality of life in multiple sclerosis pations. Shahrkord University of Medical Sciences. 2008;10(2):21-9. [Persian].

35- Naji A, Naroie S, Abdeyazdan G, Dadkani E. Effect of applying self-care orem model on quality of life in the patient under hemodialysis. Zahedan Journal of Research in Medical Sciences. 2012;14(1):8-12. [Persian].

36- Rahimi A, Salehi S, Afrasiabifar A. The Effect of Orem's Self-Care Model on Quality Of Life of Patients with Hypothyroid Goiter. Armaghane-danesh, Yasuj University of Medical Sciences Journal. 2012;17(5):398-406. [Persian].

37- Petajan JH, Gappmaier E, White AT, Spencer MK, Mino L, Hicks RW. Impact of aerobic training on fitness and quality of life in multiple sclerosis. Annals of neurology. 1996;39(4):432-41.

38- Hazrati M, Zahmatkeshan N, Dejbakhsh T, Nikseresht A, Zeyghami B. The effect of rehabilitation process on the quality of life in multiple sclerosis patients. Armaghan-eDanesh. 2005;10(3):53-64.

39-Zalewski K. Exploring barriers to remaining physically active: a case report of a person with multiple sclerosis. Journal of Neurologic Physical Therapy. 2007;31(1):40-5.

40- Rampello A, Franceschini M, Piepoli M, Antenucci R, Lenti G, Olivieri D, et al. Effect of aerobic training on walking capacity and maximal exercise tolerance in patients with multiple sclerosis: a randomized crossover controlled study. Physical therapy. 2007;87(5):545-55.

41-O'Hara L, Cadbury H, De Souza L, Ide L. Evaluation of the effectiveness of professionally guided self-care for people with multiple sclerosis living in the community: a randomized controlled trial. Clinical Rehabilitation. 2002;16(2):119-28.

42-Solari A, Filippini G, Gasco P, Colla L, Salmaggi A, La Mantia L, et al. Physical rehabilitation has a positive effect on disability in multiple sclerosis patients. Neurology. 1999;52(1):57-60. 